\title{
ORIGINALS
}

\section{Axonal Dwindling in Early Experimental Diabetes. I. A Study of Cross Sectioned Nerves}

\author{
J. Jakobsen \\ University Institute of Pathology and Second University Clinic of Internal Medicine, Kommunehospitalet, Aarhus, Denmark
}

Summary. A diminution of the cross sectional area of myelinated fibres in the common peroneal nerve was observed in rats four weeks after the induction of diabetes with streptozotocin. Small fibres were affected more than larger ones and the axon reduction was twice that of the myelin sheath. The fibre diminution and the decreased axon/myelin ratio may explain the slowing of nerve conduction in experimental diabetes.

Key words: Streptozotocin diabetes, axons, myelin sheath, nerve degeneration, neural conduction.

Peripheral nerves are involved early in juvenile diabetes. Thus Gregersen (1967) demonstrated decreased motor nerve conduction velocity within the first year after the clinical onset of the disease [1]. At this time there were no clinical symptoms of neuropathy. The structural alteration underlying this functional abnormality is still unknown.

Also in experimental diabetes, whether induced by streptozotocin, alloxan or pancreatectomy, slowing of nerve conduction occurs from the very beginning. The morphological lesion has not been identified here either.

A few histological studies have reported Schwann cell abnormalities several months after the induction of diabetes [2,3]. However, a recent extensive morphometric study failed to define any pathological alterations at all in diabetic animals [4].

In this report of early experimental diabetes quantitative morphological changes, mainly affecting the axon, are demonstrated. The pathological lesion observed in the present study may well explain the functional abnormalitiy of nerve conduction in diabetic animals.

\section{Materials and Methods}

Male Wistar rats raised on a standard rat chow diet with water ad libitum were used for the experiments. Animals 18 to 20 weeks old weighing between 330 and $380 \mathrm{~g}$ were selected at random for the different groups of the experiment. Diabetes was induced in ten rats by intravenous injection of 40 to $45 \mathrm{mg}$ streptozotocin per $\mathrm{kg}$ body weight. The animals were maintained for four weeks without insulin treatment.

Ten other rats were selected as a control group (control group 1). Both groups of animals were killed four weeks later.

For the purpose of imitating the weight loss of the diabetic rats another group of five normal animals was deprived of food for four days and subsequently fed on a restricted daily diet of nearly $50 \%$ of the standard diet for 24 days (control group 2). With this diet it was intended to induce a weight loss somewhat greater than that observed to occur in the group of diabetic rats, to compensate for the increase in gastrointestinal filling known to occur in diabetic rats.

Body weight was determined weekly in all animals. Blood glucose and $24 \mathrm{~h}$ urine output were measured at ten day intervals in the diabetic rats, and at the end of the experiment in the rats of the control groups. Blood samples were taken in the morning as duplicates from non-fasting animals. Blood glucose was determined by a glucose oxidase method [5] and urine glucose by a $\mathrm{p}$-toluidine method.

\section{Tissue Preparation}

Peripheral nerves were initially fixed by vascular perfusion. The osmolality of the fixatives and of the buffer solutions was measured by freezing-point depression (Advanced Osmometer ${ }^{\circledR}$ ). The rats were anaesthetized with a sodium pentobarbital-diazepam 


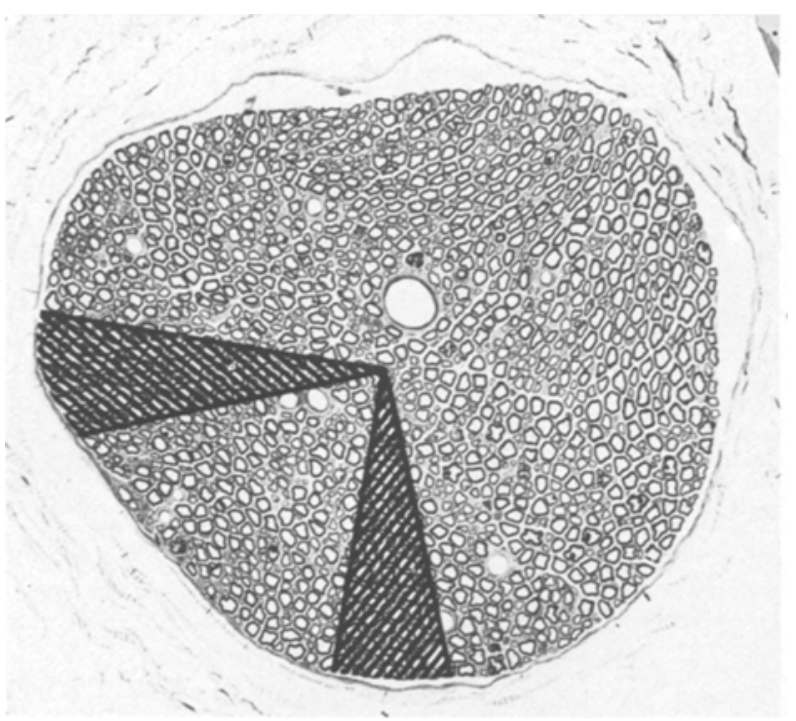

Fig. 1. Cross section of the common peroneal nerve to demonstrate sectors demarcating the two regions for measurements. Magnification $150 \times$

Table 1. Blood glucose, urine output and urine glucose after various intervals of diabetes. Results are mean values \pm SD

\begin{tabular}{llcl}
\hline $\begin{array}{l}\text { Duration } \\
\text { of } \\
\text { diabetes } \\
\text { days }\end{array}$ & $\begin{array}{l}\text { Blood } \\
\text { glucose }\end{array}$ & $\begin{array}{l}\text { Urine } \\
\text { output }\end{array}$ & $\begin{array}{l}\text { Urine } \\
\text { glucose }\end{array}$ \\
\hline 4 & $\mathrm{mg} / 100 \mathrm{ml}$ & ml per $24 \mathrm{~h}$ & $\mathrm{~g} \mathrm{per} 24 \mathrm{~h}$ \\
\hline 14 & $430 \pm 52$ & $73 \pm 18$ & $7.9 \pm 1.5$ \\
24 & $421 \pm 65$ & $147 \pm 29$ & $15.5 \pm 1.9$ \\
\hline Mean & $478 \pm 79$ & $144 \pm 29$ & $13.9 \pm 3.7$ \\
\hline
\end{tabular}

Table 2. Body weight in the two groups of controls and in diabetic animals. Results are mean values $\pm \mathrm{SD}$

\begin{tabular}{llll}
\hline $\begin{array}{l}\text { Duration } \\
\text { of the } \\
\text { experiment } \\
\text { in days }\end{array}$ & $\begin{array}{l}\text { Control } \\
\text { group I }\end{array}$ & $\begin{array}{l}\text { Control } \\
\text { group II }\end{array}$ & $\begin{array}{l}\text { Diabetic } \\
\text { group }\end{array}$ \\
\hline 0 & $\mathrm{~g}$ & $\mathrm{~g}$ & $\mathrm{~g}$ \\
\hline 4 & $347 \pm 12$ & $358 \pm 19$ & $355 \pm 17$ \\
14 & & $316 \pm 22$ & $320 \pm 14$ \\
28 & $373 \pm 17^{\mathrm{a}}$ & $271 \pm 24$ & $310 \pm 24$ \\
\hline $\begin{array}{l}\text { weight } \\
\text { change }\end{array}$ & +26 & $265 \pm 23$ & $290 \pm 29$ \\
$\mathrm{~g}$ & & $-93 \pm 6^{\mathrm{b}}$ & $-65 \pm 23$ \\
\hline
\end{tabular}

a $2 p<0.001$ compared to both corresponding groups

b $2 p<0.01$ compared to corresponding diabetic group mixture intraperitoneally and perfused intravascularly with a paraformaldehyde-glutaraldehyde fixative . $80 \mathrm{ml} \mathrm{25 \%}$ paraformaldehyde, $30 \mathrm{ml} \mathrm{25 \%}$ glutaraldehyde, $890 \mathrm{ml} 0.124 \mathrm{M}$ sodium cacodylate (bufferosmolality: $246-250$ mosmol) and $27 \mathrm{~g}$ dextran (mwt: 40000 ) per $1000 \mathrm{ml}$; total osmolality $845-857$ mos$\mathrm{mol}, \mathrm{pH} 7.35$ ). This fixative was found to give acceptable tissue preservation also at the ultrastructural level.

Between 350 and $400 \mathrm{ml}$ of the fixative was perfused through the abdominal aorta via a polyethylene tube inserted at the level of the diaphragm. The tip of the catheter was fastened just below the origin of the renal arteries. After opening the inferior vena cava, the perfusion was started at a pressure of 100 to 140 mm mercury with the hind limbs fully extended. Five minutes later the pressure was lowered to $50-60 \mathrm{~mm}$ mercury and after $20 \mathrm{~min}$ maintained at $20-30 \mathrm{~mm}$ mercury for $1^{1 / 2} \mathrm{~h}$. The whole procedure from the opening of the thoracic cavity to the start of the perfusion was carried out within less than two minutes.

After the aldehyde fixation a $1-2 \mathrm{~cm}$ long specimen of the common peroneal nerve (i. e. mixed motor and sensory nerve), $1 \mathrm{~cm}$ proximal to the penetration into the muscles of the lower leg, was cut out. This segment was chosen since no branching was observed in this part of the nerve. Following postfixation for four hrs in $2 \%$ osmium tetroxide (buffer-osmolality: 293-299 mosmols and buffer-pH: 7.45), the tissue was rinsed in the corresponding buffer, dehydrated in graded acetone and embedded in Vestopal ${ }^{\circledR}$.

$0.1-0.2 \mu \mathrm{m}$ thin transverse sections were cut on a LKB-Ultrotome ${ }^{\circledR}$ and stained with toluidine blue. Transverse sections were secured by placing the nerve perpendicular to the edge as well as to the front face of the glass knife by means of a ten times magnifying ocular fitted with cross hairs.

\section{Morphometry}

Among sections of an adequate technical quality the thinnest from each animal was chosen for measurements. The image of the section was projected on to a screen. To obtain a representative sample a sector of $22.5^{\circ}$ its vertex falling in the centre of the projected section was placed at random on the screen. The centre of the projected section was determined as the intersection of the two longest axes at right angles to each other.

Cross sections of the common peroneal nerve may have oval forms. Therefore, in order to get samples of the same relative size, measurements were performed also at another $22.5^{\circ}$ sector, perpendicular to the first one (Fig. 1).

The myelinated fibres within each sector were 
Table 3. Morphometric data of myelinated fibres in common peroneal nerves in the two groups of controls and in the diabetic animals. Results are given as whole numbers

\begin{tabular}{|c|c|c|c|c|c|c|c|}
\hline & \multicolumn{3}{|c|}{ Total values of individual nerves } & \multicolumn{4}{|c|}{ Mean values of individual fibres } \\
\hline & \multirow[t]{2}{*}{$\begin{array}{l}\text { Number } \\
\text { of nerve } \\
\text { fibres }\end{array}$} & \multirow{2}{*}{$\begin{array}{l}\begin{array}{l}\text { Nerve } \\
\text { area }\end{array} \\
\frac{\mu \mathrm{m}^{2} \times 10^{3}}{}\end{array}$} & $\begin{array}{l}\text { Fibre } \\
\text { area }\end{array}$ & \multirow{2}{*}{$\begin{array}{l}\begin{array}{l}\text { Fibre } \\
\text { area }\end{array} \\
\mu \mathrm{m}^{2}\end{array}$} & \multirow{2}{*}{$\begin{array}{l}\begin{array}{l}\text { Axon } \\
\text { area }\end{array} \\
\mu \mathrm{m}^{2}\end{array}$} & \multirow{2}{*}{$\begin{array}{l}\text { Myelin } \\
\text { area }\end{array}$} & \multirow{2}{*}{$\begin{array}{l}\text { Axon/ } \\
\text { fibre } \\
\text { ratio }\end{array}$} \\
\hline & & & $\mu \mathrm{m}^{2} \times 10^{3}$ & & & & \\
\hline \multirow{10}{*}{ 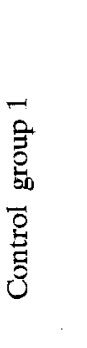 } & 1952 & 151 & 86 & 44 & 22 & 22 & 50 \\
\hline & 1792 & 134 & 80 & 45 & 22 & 22 & 50 \\
\hline & 1991 & 134 & 80 & 40 & 19 & 21 & 48 \\
\hline & 1974 & $108^{\circ}$ & 71 & 36 & 17 & 19 & 48 \\
\hline & 1944 & 129 & 82 & 42 & 19 & 23 & 45 \\
\hline & 1646 & 129 & 77 & 47 & 24 & 23 & 50 \\
\hline & 1776 & 121 & 74 & 41. & 19 & 22 & 46 \\
\hline & 1901 & 117 & 73 & 38 & 16 & 22 & 42 \\
\hline & 1873 & 127 & 78 & 42 & 21 & 21 & 49 \\
\hline & 1846 & 133 & 84 & 46 & 21 & 25 & 45 \\
\hline Mean & 1870 & 128 & 78 & 42 & 20 & 22 & 47 \\
\hline $\mathrm{SD}$ & 108 & 12 & 5 & 3 & 2 & 2 & 3 \\
\hline \multirow{5}{*}{ 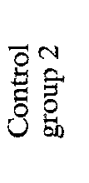 } & 1877 & 126 & 81 & 43 & 21 & 23 & 48 \\
\hline & 2111 & 147 & 94 & 44 & 22 & 22 & 51 \\
\hline & 1659 & 106 & 65 & 39 & 18 & 21 & 46 \\
\hline & 1803 & 114 & 78 & 44 & 21 & 23 & 48 \\
\hline & 1882 & 128 & 86 & 46 & 20 & 26 & 44 \\
\hline Mean & 1866 & 124 & 81 & 43 & 20 & 23 & 47 \\
\hline $\mathrm{SD}$ & 164 & 16 & 11 & 2 & 2 & 2 & 3 \\
\hline \multirow{10}{*}{ 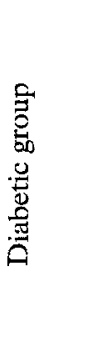 } & 1724 & 150 & 65 & 37 & 17 & 20 & 46 \\
\hline & 1737 & 137 & 67 & 39 & 17 & 21 & 45 \\
\hline & 1811 & 142 & 64 & 36 & 16 & 19 & 46 \\
\hline & 1797 & 124 & 62 & 35 & 13 & 21 & 38 \\
\hline & 2055 & 144 & 74 & 36 & 17 & 19 & 46 \\
\hline & 1927 & 113 & 64 & 33 & 16 & 17 & 48 \\
\hline & 1996 & 139 & 78 & 39 & 18 & 21 & 45 \\
\hline & 1875 & 103 & 63 & 34 & 14 & 20 & 41 \\
\hline & 1921 & 117 & 67 & 35 & 15 & 20 & 43 \\
\hline & 1965 & 147 & 75 & 38 & 17 & 21 & 45 \\
\hline Mean & 1881 & 132 & $68^{a}$ & $36^{\mathrm{a}}$ & $16^{a}$ & $20^{\mathrm{a}}$ & $44^{\mathrm{b}}$ \\
\hline SD & 111 & 16 & 6 & 2 & 2 & 1 & 3 \\
\hline
\end{tabular}

a Statistically different from the values of control group 1 and 2

b Statistically different only from the value of control group 1

counted, and the areas of the sectors, the fibres and their axons were estimated by a point-counting technique.

Point-counting for the determination of sector, fibre and axon areas was done at a magnification of $1750 \times$, employing a grid with a point density of ten points per $81.6 \mu \mathrm{m}^{2}$ and a Leitz apochromatic, aplanatic 40/0,74 objective. Total nerve areas were determined by point-counting at a magnification of $160 \times$, with a point density of 10 points per 10000 $\mu \mathrm{m}^{2}$ and a Leitz 3.5 objective.

Areas of vascular structures were point-counted and subtracted from both total nerve areas and sector areas. When a fibre was lying on a limiting line, only the part of it falling inside the sector was included.

Fibre and axon areas were size-grouped with respect to the number of points falling upon them. For nerve fibre populations of the individual rats size-frequency histograms were graphed, each bar representing the number of fibres of a given size.

All measurements were performed in one run by the author who was unaware of the identity of the specimens.

Student's t-test was employed in the statistical treatment, using a $5 \%$ limit of significance, unless otherwise stated. 

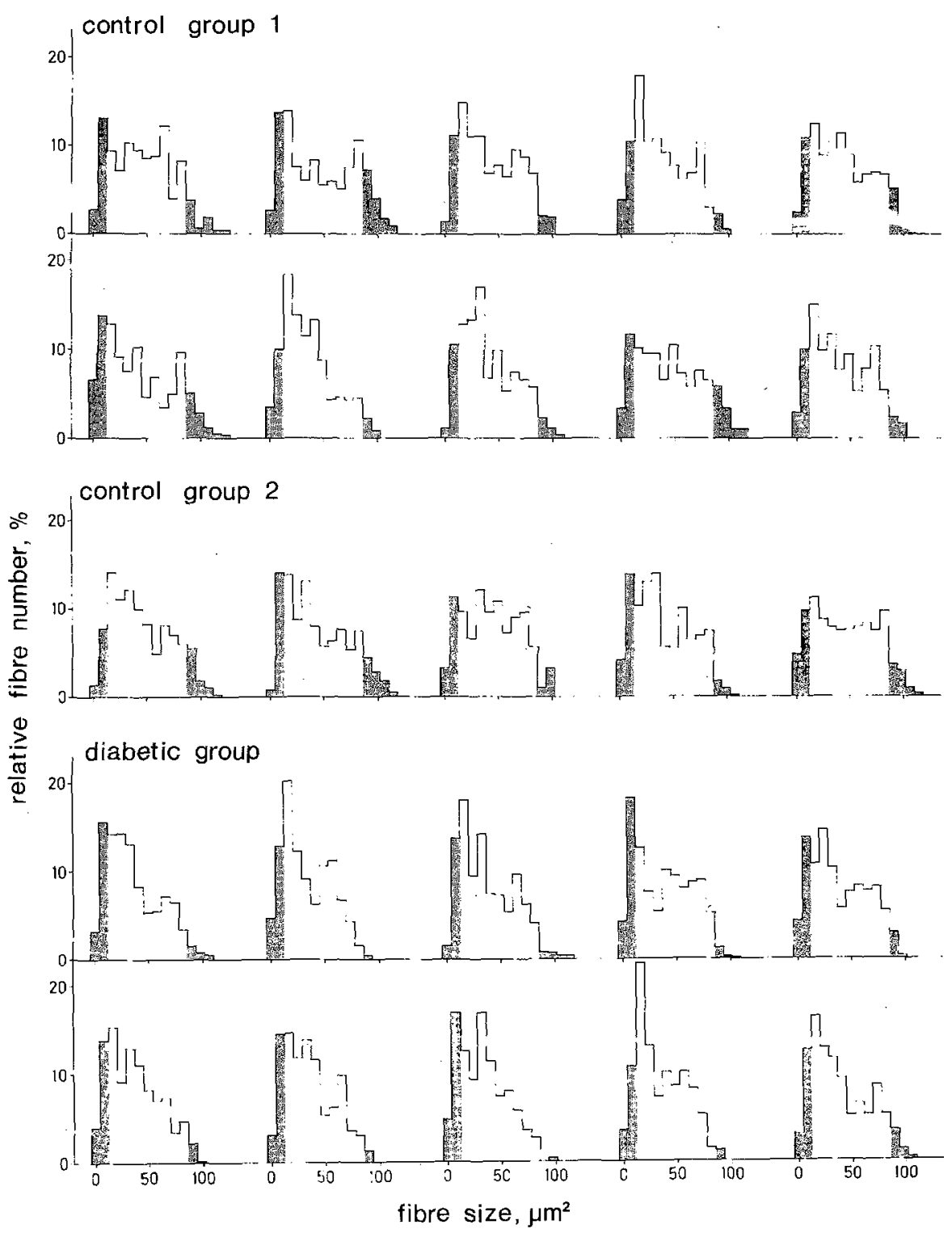

Fig. 2. Size-frequency histograms for myelinated fibres in common peroneal nerves of the ten rats in control group 1 , the five in control group 2 (restricted diet) and the ten diabetic animals. Fibres smaller than $12 \mu \mathrm{m}^{2}$ and larger than $86 \mu \mathrm{m}^{2}$ are indicated with dark columns

\section{Results}

All streptozotocin-diabetic rats developed glycosuria within $24 \mathrm{~h}$, and throughout the experiment the $24 \mathrm{~h}$ - urine output ranged from 40-200 ml per day. Glucose excretion varied with the $24 \mathrm{~h}$ urine output $(\mathrm{r}=0.95)$, the glucose concentration of the urine being approximately $10 \mathrm{~g} / 100 \mathrm{ml}$ (Table 1 ).

Blood glucose concentrations fluctuated between 300 and $600 \mathrm{mg} / 100 \mathrm{ml}$ in the diabetic group and between 80 and $110 \mathrm{mg} / 100 \mathrm{ml}$ in control group 1 . After four days of food deprivation blood glucose varied from 55 to $63 \mathrm{mg} / 100 \mathrm{ml}$ in the group of fasted animals (control group 2).
Diabetic animals had an average weight loss of $18 \%$ whereas animals of control group 1 gained $7 \%$ in body weight. As intended the weight loss of the rats in control group 2 was somewhat greater than in the group of diabetic rats, being $26 \%$ (Table 2 ).

The average number of myelinated nerve fibres occurring inside the sectors of the individual nerves was $252 \pm 31$ (SD). There was no statistically significant difference between the number of fibres in the three groups of animals.

The morphometric data are shown in Table 3. The total number of fibres in the common peroneal nerve was calculated from the number of fibres within sectors multiplied with the ratio between nerve and sec- 
tor area. The number of nerve fibres and the total nerve area were nearly identical in nerves from diabetic rats and from the two control groups.

The total cross sectional area of myelinated fibres in the diabetics was reduced by nearly $13 \%$, compared to control group 1, the arithmetic mean value being $68000 \mu \mathrm{m}^{2} \pm 5750$ as against $78300 \mu \mathrm{m}^{2} \pm 5080$ in control group $1(2 p=0.00048)$. The total fibre area in rats placed on a restricted diet (control group 2) was $80900 \mu \mathrm{m}^{2} \pm 10780$. This value is significantly different from that of the diabetic animals $(2 \mathrm{p}=$ 0.0090 ), but did not differ from that of control group 1 $(2 \mathrm{p}=0.54)$.

Since no reduction in the number of nerve fibres occurred in the diabetic group, the decrease of the total fibre area means a diminution of fibre calibre. To obtain more detailed information on the nature of the fibre-diminution size-frequency histograms were made for each rat (Fig. 2). In these diagrams a reduced number of large fibres and an increase in the number of small fibres are observed. The displacement of the diabetic fibre size distribution towards smaller values when compared to rats of control group 1 is more easily seen in the mean curves (Fig. 3). This displacement is statistically significant. Figure 4 shows the 10 th, 50th and 90 th percentiles for each rat.

The mean fibre size within the sectors was calculated for each rat using a computer program of class grouped data. The mean group value of these individual mean values of fibre size of diabetic animals was $36.15 \mu \mathrm{m}^{2} \pm 2.12$ as against a value of $42.08 \mu \mathrm{m}^{2}$ \pm 3.44 in control group 1 and $43.20 \mu \mathrm{m}^{2} \pm 2.42$ in control group 2. Thus in comparison with control group 1 an average reduction of calibre area by $14.1 \%$ has taken place in the group of diabetic nerve fibres $(2 \mathrm{p}=0.00020)$.

With the purpose of analyzing to what extent the axon and the myelin sheath are involved in the diabetic nerve fibre diminution, axon size-frequency histograms were made for all rats. A displacement of the axon distributions to the left, as described for the fibres, was observed in the diabetic group. The mean curves are shown in Figure 5.

The mean group value of the axon area, calculated in the same way as that of the fibre size, was $16.00 \mu \mathrm{m}^{2}$ \pm 1.52 compared to $19.96 \mu \mathrm{m}^{2} \pm 2.34$ and $20.43 \mu \mathrm{m}^{2}$ \pm 1.54 of control group 1 and 2 , respectively. Thus the mean axon area of the diabetic group was reduced by $19.8 \%$ in comparison with control group $1(2 \mathrm{p}=$ $0.00028)$. No significant difference in axon size between control group 1 and 2 was obtained $(2 \mathrm{p}=$ 0.69 ), whereas diabetic axons were diminished when compared to control group $2(2 \mathrm{p}=0.00014)$.

The mean myelin area is calculated for each rat by subtraction of the mean area of the axon from that of

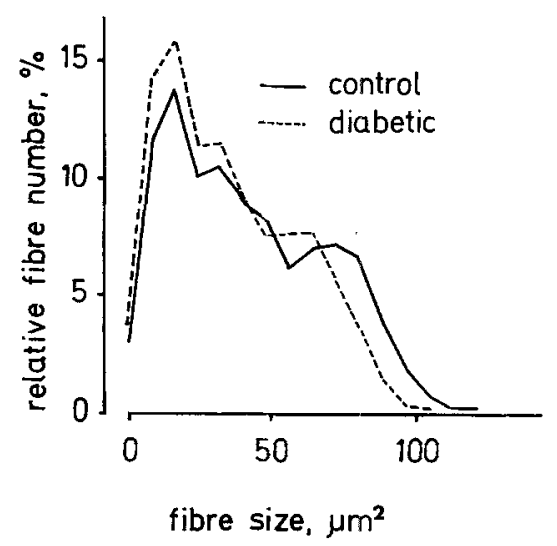

Fig. 3. Mean size-frequency distributions for all myelinated fibres in common peroneal nerves of controls (full-drawn line) and diabetic animals (dashed line)

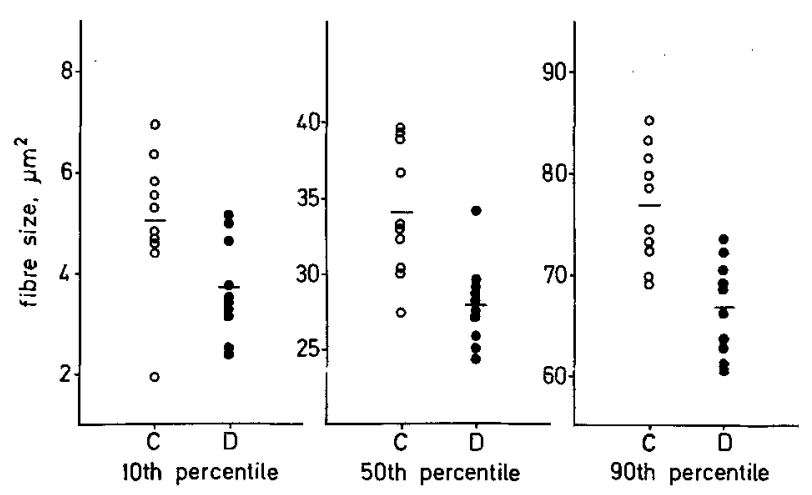

Fig. 4. Values of three percentiles of the size-frequency distributions for myelinated fibres in common peroneal nerves in each of ten controls (o) and ten diabetic animals $(\bullet)$

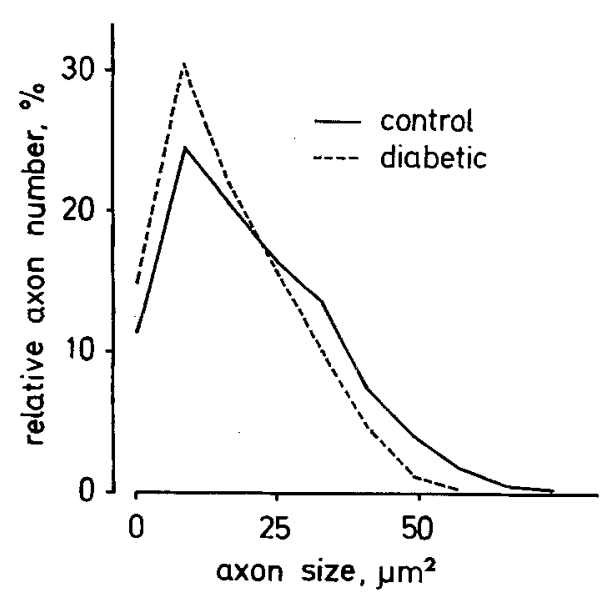

Fig. 5. Mean size-frequency distributions for all axons of myelinated fibres in common peroncal nerves of controls (full-drawn line) and diabetic animals (dashed line) 
Table 4. Fibre sizes for ten percentiles of cumulative frequency distributions in controls (group 1) and diabetic animals. Results are mean values $\pm \mathrm{SD}$. The absolute and relative fibre diminution is given in the third and fourth columns

\begin{tabular}{|c|c|c|c|c|}
\hline & $\mathrm{C}$ & D & $C-D$ & $C-D$ \\
\hline $\begin{array}{l}\text { Percen- } \\
\text { tiles }\end{array}$ & $\mu \mathrm{m}^{2}$ & $\mu \mathrm{m}^{2}$ & $\mu \mathrm{m}^{2}$ & ${ }_{\%}^{C}$ \\
\hline 10 & $5.04 \pm 1.36$ & $3.72 \pm 0.93$ & 1.32 & 26.2 \\
\hline 20 & $11.43 \pm 1.56$ & $9.14 \pm 1.19$ & 2.29 & 20.0 \\
\hline 30 & $17.95 \pm 2.59$ & $14.47 \pm 1.18$ & 3.49 & 19.4 \\
\hline 40 & $25.89 \pm 3.23$ & $20.87 \pm 1.57$ & 5.02 & 19.4 \\
\hline 50 & $34.08 \pm 4.29$ & $28.07 \pm 2.73$ & 6.01 & 17.6 \\
\hline 60 & $43.32 \pm 5.47$ & $35.89 \pm 3.45$ & 7.43 & 17.2 \\
\hline 70 & $54.11 \pm 7.20$ & $44.52 \pm 4.32$ & 9.59 & 17.7 \\
\hline 80 & $65.55 \pm 7.29$ & $56.61 \pm 4.54$ & 8.94 & 13.6 \\
\hline 90 & $76.75 \pm 5.75$ & $66.77 \pm 4.68$ & 9.98 & 13.0 \\
\hline 99 & $98.22 \pm 7.64$ & $86.37 \pm 5.84$ & 11.85 & 12.1 \\
\hline
\end{tabular}

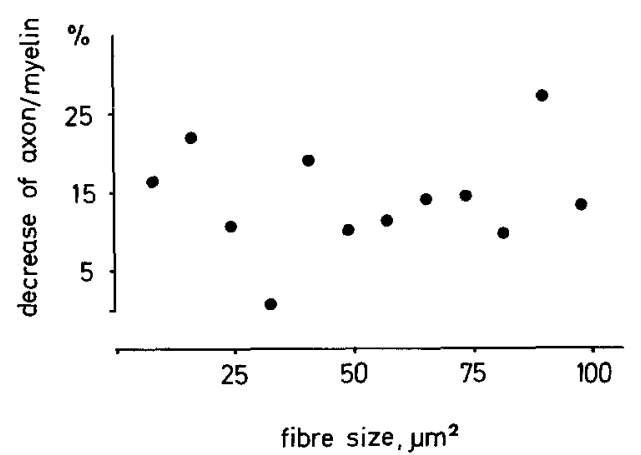

Fig. 6. Mean decrease of cross sectional axon area to myelin area ratio in relation to fibre size in all diabetic animals as a percentage of the control values

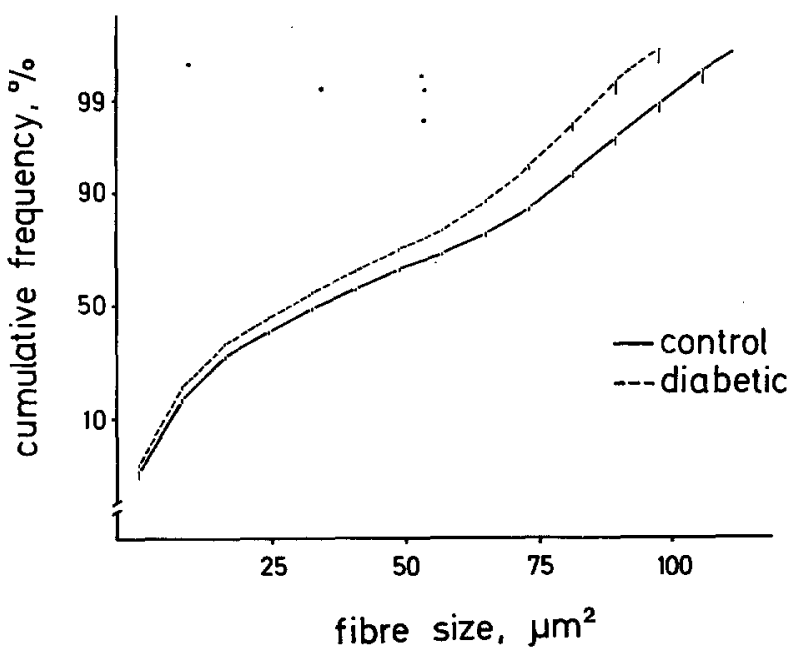

Fig. 7. Mean size-cumulative frequency distributions for myelinated fibres in common peroneal nerves of all controls (full-drawn line) and diabetic animals (dashed line). The cumulative frequencies \pm SEM are given on a probit scale the whole fibre. The mean group value of the myelin areas, again calculated as above, was $20.15 \mu \mathrm{m}^{2} \pm$ 1.29 in the diabetic group, $22.12 \mu \mathrm{m}^{2} \pm 1.66$ in control group 1 and $22.77 \mu \mathrm{m}^{2} \pm 1.77$ in control group 2 . The difference between the diabetics and control group 1 amounts to $8.9 \%(2 p=0.0081)$. In comparison with control group 2 the myelin sheath of the diabetic animals was also reduced $(2 p=0.0059)$. No significant difference between control group 1 and 2 was obtained $(2 p=0.50)$.

From the mean area values of each rat, axon/fibre ratios and axon/myelin ratios were computed. Both of the ratios were significantly decreased in diabetic animals in comparison with control group $1(2 p=0.02)$.

To examine the possibility of a relation between fibre size and axon-myelin ratio, the ratios were calculated in twelve size-classes of fibres. In all classes the mean ratio of the controls exceeds the ratio of the diabetics. Figure 6 shows the difference between the ratios of the diabetics and those of control group 1 plotted against fibre size. No correlation between these differences and fibre size was obtained $(2 p=$ 0.72 ).

The relative size-cumulative frequency distributions of diabetics and controls based on the values of the size-frequency histograms are shown in Figure 7. The fact that the curve of the diabetics is displaced towards smaller values without points of intersection with the control curve indicates the involvement of all sizes of nerve fibres in the process. The nerve fibre diminution was calculated for ten percentiles by linear interpolation. The values are given in Table 4. Fibre size was positively correlated $\left(r_{s}=0.99\right.$, Spearman's rank coefficient) with the fibre diminution $(2 \mathrm{p}<$ $0.001)$. However, a negative correlation was obtained $\left(r_{s}=-0.96\right)$ when the fibre diminution was expressed on a percentage basis $(2 p<0.001)$. In other words, small fibres were relatively more involved than larger ones.

\section{Discussion}

In this study of a mixed motor and sensory nerve in early experimental diabetes a reduction of the cross sectional fibre area involving all myelinated fibres is demonstrated. Small fibres are relatively more affected than larger ones. The reduction of the axon is twice that of the myelin sheath and the relationship between the cross sectional axon and myelin area is uniformly decreased for all fibre sizes.

An earlier study of nerve fibre size in experimental diabetes relied upon measurement of nerve fibre diameter [4]. This is difficult, however, because the cross sectioned nerve fibres often have many other 
forms than circles or ovals. The correct way of estimating fibre size is a determination of the area on cross sections. This can be done with great precision using a point counting technique as done in the present study.

For comparison with other similar studies attention is again drawn to the fact that the values discussed here are areas, not diameters. The $14 \%$ area reduction in diabetic animals would correspond to about a $7 \%$ reduction in diameter.

Fibre size increases with age $[4,6]$. Since diabetic and control animals were matched with respect to age, weight and sex the decreased mean cross sectional fibre area reported here cannot be ascribed to these factors.

In a study of malnutrition a decreased nerve fibre diameter was found in 180 day old rats submitted to a fifty percent food restriction from conception [7]. In the present study a control group fed a restricted diet for four weeks, having a weight loss comparable to that of the diabetic animals, showed no reduction of fibre size. It therefore seems unlikely that malnutrition could be the explanation of the present findings.

Whether dehydration gives rise to nerve fibre diminution is not known. However, the animals used in this study were offered water ad libitum and rats with a diabetic state similar to the one used here showed no decrease of the total water content of sciatic nerves (unpublished data).

The osmolality of the perfusion fixatives was maintained within a very narrow range. However, it cannot be excluded that the histological preparation affects diabetic tissue in a different way, when compared to normal tissue. As the osmololatiy of diabetic tissue in this experiment must have been increased by the same 20 mosmol as that of the serum this would tend to result - if anything - in fibre swelling.

Another report deals with a study of isolated nerve fibres from the rats used in the present study [8, 9]. It appears from this study that decreased nerve fibre thickness in diabetic rats can also be shown with this technique. This indicates that neither dehydration in acetone nor plastic embedding is responsible for the nerve fibre diminution.

There is one report in the literature dealing with quantitative estimation of cross sectional nerve fibre thickness in experimental diabetes (Sharma and Thomas, 1974) [4]. From their study of streptozotocin and alloxan diabetic rats, with a duration of diabetes of 3 to 53 weeks, it was concluded that there was no evidence of a reduction in myelinated fibre diameter. The reason why they failed to demonstrate a diminution of nerve fibre calibre could be that their results from diabetic and control animals were not compared for the identical age groups.

Very few quantitative data from peripheral nerves of diabetic patients are available. In a study of Chopra and Hurwitz (1969) of the cross-sectioned sural nerve in 16 diabetics some displacement of frequency-size histograms towards smaller values can be seen [10]. The authors suggest that this result may be due to loss of large fibres or remyelination following segmental demyelination. It may also be explained, however, by a diminution of the fibre calibre.

A loss of large myelinated fibres was observed by Greenbaum (1964) in short-term diabetics [11]. Since the number of fibres was not counted in that study, fibre diminution, without loss of fibres, may have occurred.

It has been known for many years that animals with experimental diabetes have decreased nerve conduction velocity $[12,13,14,15]$ - just like diabetic patients. This reduction is present two weeks after the induction of the diabetic state.

The slowing of the nerve impulse may be determined by an interplay of many factors [16]. Two of the findings of the present study can contribute, namely the fibre diminution and the altered axon/fibre ratio.

It is well known that reduced nerve fibre calibre slows conduction $[17,18]$. The relationship between conduction velocity $(\theta)$ and fibre diameter (D) obtained in studies of single nerve fibres is approximately $\theta=1.5 \mathrm{D}^{1.5}[19]$. In the present study the cross sectional area of large diabetic nerve fibres (the 90th percentile, table 4) was diminished by $13 \%$.

When this diminution is recalculated as a difference in diameter, assuming cylindrical shape of nerve fibres, it appears that it can account for a $10 \%$ reduction in nerve conduction.

For a given fibre calibre the time of conduction is influenced by the axon/fibre ratio. When the axon/ fibre ratios of the present study are converted in the same way, the axon diameter/fibre diameter ratios turn out to be 0.69 and 0.67 respectively in controls and diabetic animals.

These values can be interpreted using results from a computer simulation study of fibre and axon diameter [20]. In this way it is seen that the difference between the two ratios mentioned can account only for a change of $2 \%$.

All in all the morphometric data presented here may be the structural basis underlying an $8-12 \%$ reduction in nerve conduction velocity.

Various authors have reported reduction of motor conduction velocity of 10 to 30 per cent $[4,12,14]$. Using the tail nerve method which has considerable advantages over other techniques, Miyoshi and Goto [13] and Fox [15] found a reduction of 10.5-14\% after six weeks and three months respectively, of diabetes.

The much more pronounced slowing of the nerve 
impulse reported by some authors in other studies may perhaps be explained by a decrease in conductivity of the axoplasm, leakage of current through abnormal myelin, ion abnormalities at the nodal membrane and increase of the external resistance of the medium surrounding the nerve fibres. Such changes do not at present have any known morphological correlates.

\section{References}

1. Gregersen, G.: Diabetic neuropathy: Influence of age, sex, metabolic control, and duration of diabetes on motor conduction velocity. Neurology 17, 972-980 (1967)

2. Preston, G. M.: Peripheral neuropathy in the alloxan-diabetic rat. J. Physiol. 189, 49P-50P (1967)

3. Hildebrand, J., Joffroy, A., Graff, G., Coërs, C.: Neuromuscular changes with alloxan hyperglycemia. Arch. Neurol. 18, 633-641 (1968)

4. Sharma, A. K., Thomas, P. K.: Peripheral nerve structure and function in experimental diabetes. J. neurol. Sci. 23, 1-15 (1974)

5. Ørskov, H., Juel Christensen, N.: Growth hormone in uremia. 1. Plasma growth hormone, insulin and glucagon after oral and intravenous glucose in uremic subjects. Scand. J. clin. Lab. Invest. 27, 51-60 (1971)

6. Schlaepfer, W. W., Myers, F. K.: Relationship of myelin internode elongation and growth in the rat sural nerve. J. comp. Neurol. 147, 255-266 (1973)

7. Sima, A., Jankowska, E.: Sensory nerve conduction velocity as correlated to fibre size in experimental undernutrition in the rat. Neuropathology and Applied Neurobiology. 1, 31-37 (1975)

8. Jakobsen, J.: Reduced nerve fibre diameter in acute experimental diabetes. Diabetologia 11, (Abstr.) 352 (1975)

9. Jakobsen, J.: Axonal dwindling in carly experimental diabetes. II. A study of isolated nerve fibres. Diabetologia 12, 547-553 (1976)
10. Chopra, J. S., Hurwitz, L. J.: Sural nerve myelinated fibre density and size in diabetics. J. Neurol. Ncurosurg. Psychiat. 32, 149-154 (1969).

11. Greenbaum, D., Richardson, P. C., Salmon, M. V., Urich, H.: Pathological observations on six cases of diabetic neuropathy. Brain 87, 201-214 (1964)

12. Eliasson, S. G.: Nerve conduction changes in experimental diabetes. J. clin. Invest. 43, 2353-2358 (1964)

13. Miyoshi, T., Goto, I.: Serial in vivo determinations of nerve conduction velocity in rat tails. Physiological and pathological changes. Electroenceph. clin. Neurophysiol. 35, 125-131 (1973)

14. Greene, D. A., DeJesus, P. V., Winegrad, A. I.: Effects of insulin and dietary myoinositol on impaired peripheral motor nerve conduction velocity in acute streptozotocin diabetes. J. clin. Invest. 55, 1326-1336 (1975)

15. Fox, C., Lowy, C., Wright, V.: The effect of diabetic control on motor nerve conduction velocity. Diabetologia 11, (Abstr.) 342 (1975)

16. Scott, A. C.: The electrophysics of a nerve fiber. Rev. Mod. Phys. 47, 487-533 (1975)

17. Rushton, W. A. H.: A theory of the effects of fibre size in medullated nerve. J. Physiol. 115, 101-122 (1951)

18. Noble, D.: The nerve impulse. In: The peripheral nervous system (ed. J. I. Hubbard), pp. 27-45. New York and London: Plenum Press 1974

19. Coppin, C. M. L., Jack, J. J. B.: Internodal length and conduction velocity of cat muscle afferent nerve fibres. J. Physiol. 222, 91P-93P (1972)

20. Smith, R. S., Koles, Z. J.: Myelinated nerve fibres: Computed effect of myclin thickness on conduction velocity. Amer. J. Physiol. 219, 1256-1258 (1970)

Received: April 20, 1976, and in revised form: July 9, 1976

Dr. J. Jakobsen

Research Fellow

Second Univ. Clinic of

Internal Medicine

Kommunehospitalet

DK-8000 Aarhus C

Denmark 